\title{
The Obstacles and Strategy of Building Information Modeling Application in Chinese Construction Industry
}

\author{
Boya Ji, Zhenqiang Qi, and Zhanyong Jin
}

\begin{abstract}
At present, there is a difficult situation in promoting and applying Building Information Modeling (BIM) in China. Many Chinese scholars made summaries of a range of obstacles in different practices; however, there is no clear guidance and effective strategy from which they can learn and enhance their capacity in using BIM. In this paper, we analyze the BIM application in China and seek to present what is the most reasonable strategy, which is inevitably impeded by the result of the existence of externalities. Moreover, analysis of the obstacles and establishments of Dynamic Game Model based on complete information are firstly proposed among enterprises and government. The overall aim of the Model is to find the relations between government and participants, and to discover the practice method in BIM application. It is concluded that the government with the most powerful influence on the promotion of BIM application is expected to formulate corresponding policies to improve BIM's development. Notably, since the Economic Efficiency, the main influential factor for BIM applications, leads economic incentive policies to be in charge of popularizing and deepening BIM applications, the degree of motivation becomes a key element to promote BIM technology. Therefore, we can rationally figure out that the government should strengthen the BIM technology research and its development in order to solve the problems or obstacles of BIM applications.
\end{abstract}

Index Terms-Building Information Modeling (BIM), obstacles, externality, game model.

\section{INTRODUCTION}

In 2002, the Autodesk Company reported "the White Paper of Autodesk Industry Solutions", which made the accurate definition of BIM: Building Information Modeling (BIM) not only creates and operates on digital databases for collaboration, but also manages any coordinated component and preserves information [1]. Hence, in order to promote the application and popularization of BIM in China, what is required in china is the development of BIM products (software, computer and network platform, etc.) as well as a sequence of concerns about the practical situation of Construction Project Management. Only in this way can BIM be adopted easily and quickly. If necessary, some efficient policies regarding economic incentives should be formulated to provide supports. In China, there are numerous companies that have developed some relational software products helping to overcome obstacles of BIM application on the technical stage, such as Glodon, Lobn, and Tangent. However, the popularizing rate of BIM

Manuscript received January 23, 2014; revised March 20, 2014.

The authors are with the Beijing University of Civil Engineering and Architecture-BUCEA, Department of School of Economics and Management Engineering, Beijing 100044, China (e-mail: jbylucifer@gmail.com, qizhenqiang@bucea.edu.cn,jzy03322@163.com). application is still low, and also the penetration degree is not getting higher in Chinese Construction Industry. This paper focuses on the study of economic impacts on BIM application, and makes the analysis of BIM application obstacles by using economic theories for the first time. As a result, specific strategies and suggestions are put forward to solve those problems of BIM applications.

\section{LITERATURE REVIEW}

A literature review is performed to analyze the problems and obstacles in the application of BIM. A majority of scholars have put forward obstacles through summarizing or sourcing from sporadic experimental practices. In addition, these papers are selected from the collections published within the past three years. Wang Guangbin combined the experience of Europe \& USA with Chinese national conditions to claim that the benefits that different enterprises get affect the participants' applying of BIM [2]. Zhang Chunxia, who emphasized the participants' influence, presented that the participants came to a deadlock due to numerous obstacles, including the difficulties of design synergy, and thus indicating that the less owners understood BIM, the less developed software functions came true [3]. Ying Yuken generalized/summed up/concluded that enterprises desiderated to bring in all sorts of BIM talents to the save life-cycle processes of the project, for instance, technological developers, servicers and maintainers. However, the introduction and training of the BIM talents would be a burden to the total cost [4]. Geng Yuelong concluded that since the time when the benefits of BIM were not larger than the cost of investment, and the profit was not obviously high in the short-term investment, enterprises are unwilling to invest more capital to the market. [5]. BIM is a fresh matter in china; therefore, it lacks competitiveness in the aspect of cost and popularity. The congeneric product $\mathrm{CAD}$ is more mature in Chinese market. As a result, enterprises do not want to change the current status recklessly and they remain choose CAD just for safety's sake. Moreover, the investigation report shows that, China has not reached the level of BIM standard system, which limits both the application and popularization of BIM technology [6]. He Qinghua put forward that BIM software which was used to set up an independent framework, consequently was difficult to reduce the cost for the software supports, which were required in the repeated construction of frameworks [7]. Zhu Jiajia believed that it was easy for BIM management model to produce the ownership, and the lack of work platform leaded low execution efficiency, and etc. [8]. Zhang Lianying surveyed among the Chinese construction companies for the situation of BIM's application, which revealed lots of issues against 
technology, personnel, organization, law, and industry in the application process [9]. Through inquiring about the actual status of BIM applications by construction enterprises, Ma Zhiliang alleged that the difficulties in understanding of BIM and mastering the technical ability leaded to the low utilization rate of BIM application in Construction enterprises [10]. In addition, Darius Migilinsk as summarized various obstacles pointedly in the 11th MBMST in 2013 [11]. Gong Yanxi enumerated a range of successful cases of BIM, and summarized that the development of BIM software was in a low degree and the existing policies and standards for BIM was not perfect yet [12]. All above, many Chinese experts have summarized the obstacles of BIM application and attempted to give some feasible suggestions. , we find that, to sort those reminded obstacles, former scholars classified those obstacles into four aspects: Technology, Economy, Organization and Personnel (See Table I).

TABLE I: ENCOUNTERED PROBLEM OF BIM APPLICATION

\begin{tabular}{cccc}
\hline \multicolumn{4}{c}{ TABLE I: ENCOUNTERED PROBLEM OF BIM APPLICATION } \\
\hline Technology & Economical & Organization & Personal \\
\hline$[3],[5]$, & {$[4],[5],[7],[9]$} & {$[3],[6],[8],[9]$,} & {$[2]-[5]$,} \\
{$[8]-[12]$} & {$[11],[12]$} & {$[9],[10]$} \\
\hline \hline
\end{tabular}

From the aspect of practical experience and research, scholars speculated that the obstacles of the BIM application and popularization were complex. But they failed to find the root reason and haven't put forward reasonable and appropriate strategy or suggestions. It seems that most obstacles are found through actual operation and most of them have no clue to solve, even the surface problem. Therefore, many strategies are just compliant to the status quo but have less value to guide the future. Besides, we can find that no matter whether the leading/prominent authors considered the BIM application as a block from Economy, the promotion and development of BIM will connect with economy directly or indirectly. All problems may aggravate the cost and then consequently cause more obstacles due to the insufficient cost. In order to find the foundation problem on BIM application we must consider the economic affects. The emphasis on this paper is to find out the primary reason why BIM is applied and popularized so slowly and dedicate to giving the theoretical foundation from economic externality. Finally, by using the Game model, the paper will put forward the reasonable advice of settlement on the sight of the government.

\section{PRINCIPLES AND METHODS OF EXTERNALITIES}

In fact, many economic obstacles can be avoided during the BIM application in China, because the market did not reach the Pareto Optimal State. The main cause of market failure generally includes the following factors: Monopoly, Externality, Public goods and Incomplete Information [13]. The BIM applications are not popular in the Chinese market, so monopoly has not formed. In addition, as an emerging technology, BIM requires payment. Therefore, BIM economic block mainly comes from the economic benefits of BIM itself and the Positive Externalities.

\section{A. Definition}

It has been a widespread and proper concept in the book of Western economics that Economic Externality is a non-market additional effect between economic subject and other economic subject in the process of production or consumption. Namely, economic subjects are engaged in an economic behavior, but the costs and consequences are not fully borne by itself [13]. There are no explicit description better than it.

There are many classification method of Externalities externality. It could be categorized into 2 parts: Positive Externality and Negative Externality (or External Economies and External Diseconomies). The phenomenon in which Economic subject does some economic activities bringing benefit to other society without being paid is called a "Positive Externalities"; on the contrary, the phenomenon, in which Economic subject does some economic activities bringing damages to others or society without compensation for victims, is called a "negative externality". Dr. Hong Manjiang [13] adopts another way to classify "Externalities externality": One-way Externalities and Interaction Externalities. One-way externality is brought by only one party to another party External Economies or External Diseconomies irreversibly. External Interaction is that all the parties have the right to pay or be paid for each other.

\section{B. The Production of Externalities of BIM}

There are three main parts in Construction, including owner, designer, and contractor. BIM as a 3D information model can make the space design. But it is difficult to achieve the technology of 2D-CAD.Companies can take advantage of BIM to improve the quality of building model and make it more artistic, clearer and more direct. All above advantages can help users reduce costs, save time and improve efficiency. When three main participants are using BIM in the same time, the information transfer can achieve higher quality and faster speed. Therefore, each single participant using BIM by oneself can share efficient information with other enterprises and for other convenience as well [14]. Every enterprise has positive externalities through the interaction during the application process.

In addition, the implementation of BIM can improve the whole industry's informatization development, strengthen information industry's circulation and accelerate the progress of industry, which are of great benefit to construction industry development. As all of these instruction shows, BIM products for the whole construction have the characteristics of positive externalities.

\section{The Hazard of Externalities of BIM}

When BIM application creates External Economies, the marginal cost of the society, represents as " $M C+M E$ ", is below to marginal cost of enterprises, represents as" $M C$ ", so the marginal cost curve of the society is at the bottom of the marginal cost curve of the enterprises. When enterprise pursues to the profit maximization, the degree of BIM application is in point " $X_{1}$ ", but the social benefits maximization of BIM application degree of investment should be in point" $X_{2}$ ", clearly“ $X_{1}<X_{2}$ ", which doesn't reach Pareto Optimality of BIM required by investment degree (refer with Fig. 1)." $M C$ "symbolizes the marginal cost curve of enterprises. " $M E$ " symbolizes external cost curve. " $M R$ "symbolizes the marginal income curve. " $D$ " 
symbolizes demand curve.

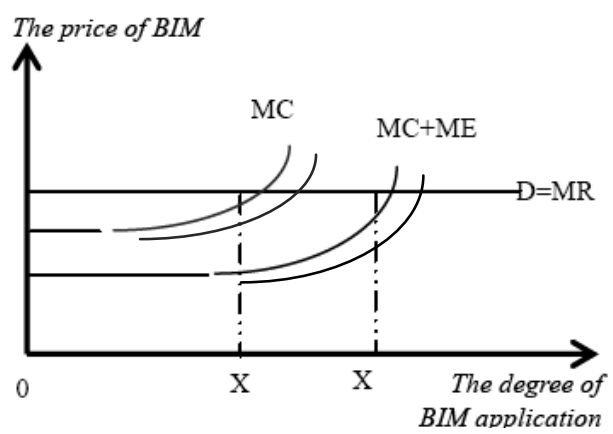

Fig. 1. The positive externalities of BIM investment.

Assuming that all enterprises are rational and the private interests of enterprises take an action " $V_{P}$ ", which brings social benefits" $V_{S}$ ". Then, the private cost of enterprise operation" $C_{P}$ " has two kinds of situation: (i) When “ $C_{P}<V_{P}<V_{S}$ "and" $V_{P}<V_{S}$ ", enterprises will not continue to go on with BIM technology investment until" $C_{P} \nless V_{P}$ ”. So on this stage developing BIM technology depends on the BIM cost-benefit differences. (ii) When" $V_{P}<C_{P}<V_{S}$ ", enterprise will stop investing in BIM technology. On this stage the economic reason that hinders the application of BIM reason comes from External Economies. With the improving of investment and " $M C$ ", the situation (i) will change gradually to situation (ii) and the cut-off point is " $C_{P}=V_{P}<V_{S}$ ". The point demarcates the obstacles from enterprise's internal efficiency and externalities.

\section{The Obstacle Analyzes about the Externalities of Enterprises}

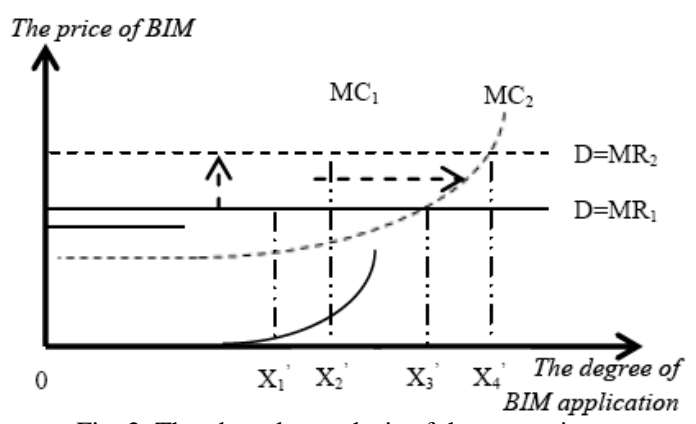

Fig. 2. The obstacles analysis of the enterprises.

In view of the situation (i) we can improve the efficiency of BIM technology to help enterprises to reduce the marginal cost of BIM, so that it will improve the BIM marginal benefit and lead to enhance BIM investment degree. (refer to Fig. 2). The past marginal cost " $M C_{1}$ " will down and the marginal cost curve will go to the right and become " $M C_{2}$ ". In the same time, " $M R_{1}$ " will go down to become " $M R_{2}$ ". The investment degree goes up from " $X_{1}^{\prime}$ " to " $X_{4}^{\prime}$ ". But " $M E$ " will not be influenced and the situation (ii) is also constant. According to the situation of investment increasing, the " $M E$ "will increase too. Therefore, "
$M E_{1} \ngtr M E_{2}$ " (refer to Fig. 3). Positive Externalities of BIM application obstacles still exist.

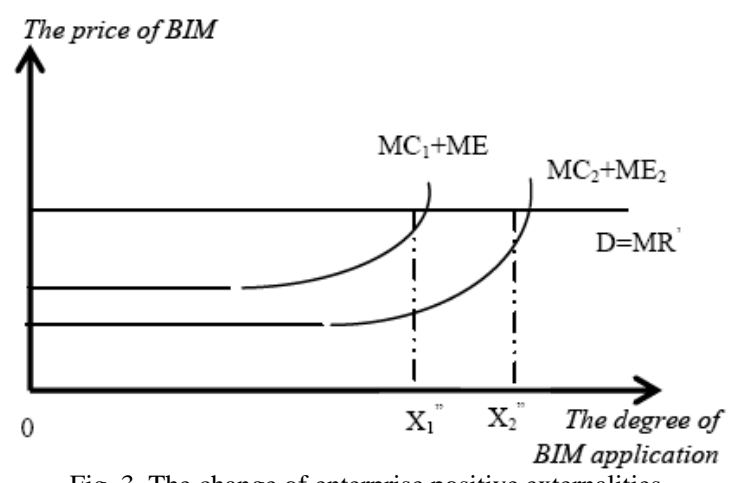

Fig. 3. The change of enterprise positive externalities.

McGraw Hill Construction has reported "The Business Value of BIM" that only senior BIM users see the advantages of BIM platform of information sharing, a large number of novices are skeptical to popularize BIM [16]. It can be explained basing on economic externality that companies are dissatisfied with others who enjoy beneficial effect without paying for them, but they excuse themselves naturally. If government couldn't solve the "free rider" behavior in the market, companies will run out of steam to implement BIM application by themselves [17]. Therefore, when social Pareto Optimality condition has not been implemented, there is gap to Pareto optimum, just like in the situation (ii).The benefits of BIM applications have not all received by investment companies so that it needs a portion of compensation from the other beneficiary in society, which government should regulate and control in macroeconomic.

\section{BIM APPLICATION SOLUTION DESIGN}

\section{A. The Relationship between Participants Related to BIM}

Three main parties in Construction are involved in the relationship, in addition to the government, as the market leader, whose role is to advocate and promote the application of BIM. (Refer to Fig. 4).

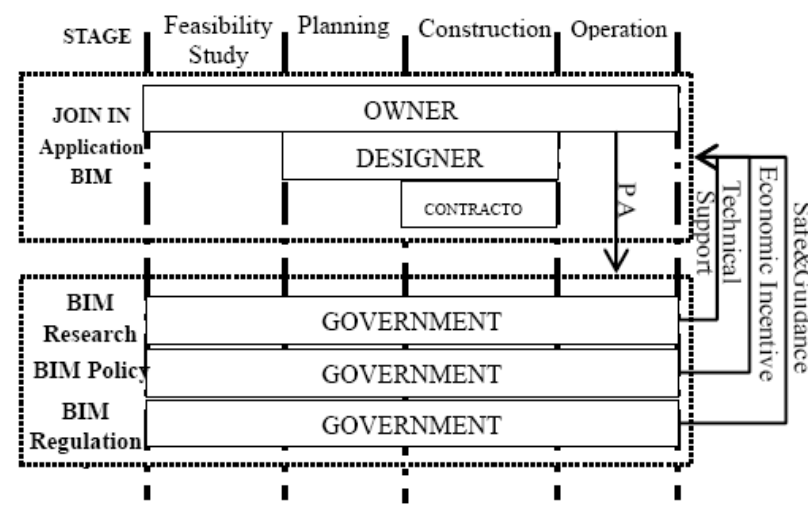

Fig. 4. The relationship between government and enterprises.

\section{B. The Government Is the Most Powerful Factor to Overcome the BIM Economic Obstacles}

On the one hand, the government as a representative of the society enjoys benefits from technology related to BIM. On the other hand, it is also the only constituent for policies 
and regulations. It is the duty of government to enact these instructions on behalf of public interest, corresponding to technical specification. So government should build BIM public information platform for participants and establish BIM technical standards and specifications. In addition, according to China's national conditions, the backbone of the domestic scientific research strength is mainly concentrated in universities and research institutes rather than companies; it is also an essential factor for government to raise BIM technology and increase standard research.BIM characters Public Goods, so its development mainly comes from the macro guidance of the national government. Coordinating the relationship among the enterprises of the interests' side in BIM application, improving the economic benefits of BIM, meanwhile solving the positive externalities of BIM application block, all above need the government to provide technical supports, enact economic policy guidance and criterion for BIM application's favorable prospect.

\section{The Complete Information Dynamic Game Model between Government and Enterprise}

\section{1) The model of strategy}

1) Participant: Government (abbr. g) \&Enterprises applying BIM (abbr. e).

2) The action sequence: the government is first and then these enterprises plan the BIM application investment.

3) The action space: Government can decide whether to implement economic incentive policy, indicated as $I=\left(I_{1}, I_{2}\right)=$ (implement, non-implement $)$. And then, enterprises can decide whether to pay more money to BIM, indicated

$P=\left(P_{1}, P_{2}\right)=($ payment, non-payment $)$.

4) The strategy space of all participants: Government has one set of information and two action plans, indicated as $S_{g}=\left\{I_{1}, I_{2}\right\}$. Enterprises have two set of information and four action plans, indicated as $S_{e}=\left(\left\{P_{1}, P_{1}\right\},\left\{P_{1}, P_{2}\right\},\left\{P_{2}, P_{1}\right\},\left\{P_{2}, P_{2}\right\}\right)$.

Games between the government and the construction enterprises are in accordance with complete information dynamic Game model (refer to Fig. 5).

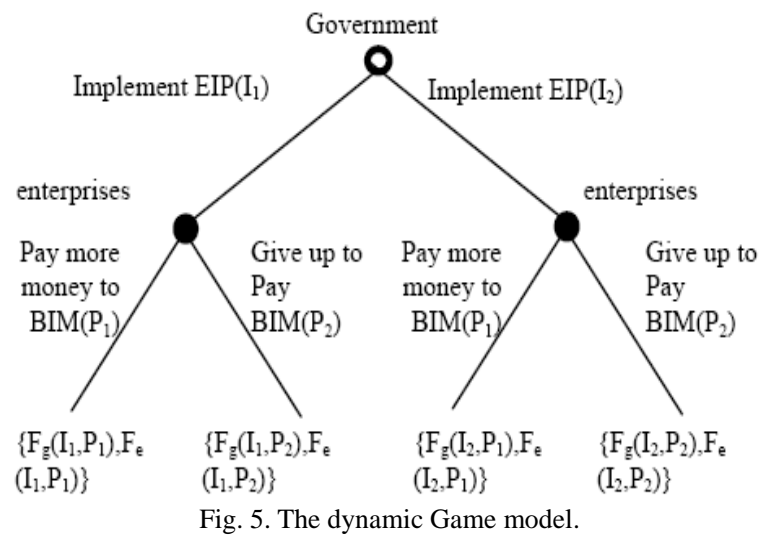

5) Participants in the payoff function: Assuming revenue of enterprises is represented as " $S_{b}$ ", indicated as $b=(m, n)=($ applicationBIM, non-aplicationBIM $)$, clearly" $S_{m}>S_{n}$ ".Assuming cost of enterprises is represented as " $C$ " by the action plan decision, indicated as" $C=c\left(P_{i}\right), i=1,2$ ". The cost of economic incentive policy is represented as " $x$ " and the yield is represented as" $y$ ". Therefore, the action strategy is decided by government and enterprises, indicated as" $\mathrm{X}=x\left(I_{i}, P_{i}\right), i=1,2$ ”. Payoff function is represented as $F_{g}=y\left(I_{i}, P_{i}\right)-x\left(I_{i}, P_{i}\right)$.

2) Modeling

1) When" $\left[S_{m}-c\left(P_{1}\right)\right]>\left[S_{n}-\mathrm{c}\left(P_{2}\right)\right]$ ", on the other words, the benefits of those enterprises applying BIM are greater than the ones not. Enterprises have two plans:

When the situation is “ $I_{1}$ ”, so " $I_{1}: \max \left\{F_{e}\right\}=\max \left\{F_{e}\left(I_{1}, P_{1}\right), F_{e}\left(I_{1}, P_{2}\right)\right\} "$, the optimal solution of enterprises is “ $P^{*}\left(I_{1}\right)=P_{1}$ ”, enterprises can pay more money to BIM.

When the situation is " $I_{2}$ ", so " $I_{2}: \max \left\{F_{e}\right\}=\max \left\{F_{e}\left(I_{2}, P_{1}\right), F_{e}\left(I_{2}, P_{2}\right)\right\} "$, the optimal solution of enterprises is " $P^{*}\left(I_{2}\right)=P_{1}$ ”, enterprises can pay more money to BIM.

Therefore, the optimal function of government is" $\max \left\{F_{g}\right\}=\max \left\{F_{g}\left(I_{1}, P_{1}\right), F_{g}\left(I_{2}, P_{1}\right)\right\} "$, so the optimal solution of government is " $I^{*}\left(P_{1}\right)=I_{2}$ ”, government does not have to implement economic incentive policy.

2) When" $\left[S_{m}-c\left(P_{1}\right)\right]<\left[S_{n}-\mathrm{c}\left(P_{2}\right)\right]$ ", on the other words, the benefits of the enterprises applying BIM are lower than the ones not. Enterprises inclined to consider whether the government action will pay for their loss.

If $x<\left[S_{n}-\mathrm{c}\left(A_{2}\right)\right]-\left[S_{m}-c\left(A_{1}\right)\right]$ :

When the situation is " $I_{1}$ ”, so " $I_{1}: \max \left\{F_{e}\right\}=\max \left\{F_{e}\left(I_{1}, P_{1}\right), F_{e}\left(I_{1}, P_{2}\right)\right\} "$, the optimal solution of enterprises is " $P^{*}\left(I_{1}\right)=P_{2}$ ", enterprises cannot pay more money to BIM.

When the situation is " $I_{2}$ ", so " $I_{2}: \max \left\{F_{e}\right\}=\max \left\{F_{e}\left(I_{2}, P_{1}\right), F_{e}\left(I_{2}, P_{2}\right)\right\}$, the optimal solution of enterprises is “ $P^{*}\left(I_{2}\right)=P_{2}$, enterprises cannot pay more money to BIM.

Therefore, the optimal function of government is" $\max \left\{F_{g}\right\}=\max \left\{F_{g}\left(I_{1}, P_{2}\right), F_{g}\left(I_{2}, P_{2}\right)\right\} "$, so the optimal solution of government is “ $I^{*}\left(P_{1}\right)=I_{2}$ ”, government gives up implementing economic incentive policy.

If $x>\left[S_{n}-\mathrm{c}\left(A_{2}\right)\right]-\left[S_{m}-c\left(A_{1}\right)\right]$ :

When the situation is " $I_{1}$ ”, so $I_{1}: \max \left\{F_{e}\right\}=\max \left\{F_{e}\left(I_{1}, P_{1}\right), F_{e}\left(I_{1}, P_{2}\right)\right\} \quad, \quad$ the optimal 
solution of enterprises is $P^{*}\left(I_{1}\right)=P_{1}$, enterprises can pay more money to BIM.

When the situation is " $I_{2}$ ", so $I_{2}: \max \left\{F_{e}\right\}=\max \left\{F_{e}\left(I_{2}, P_{1}\right), F_{e}\left(I_{2}, P_{2}\right)\right\}$, the optimal solution of enterprises is " $P^{*}\left(I_{2}\right)=P_{2}$ " , enterprises cannot pay more money to BIM.

Therefore, the optimal function of government is $\max \left\{F_{g}\right\}=\max \left\{F_{g}\left(I_{1}, P_{1}\right), F_{g}\left(I_{2}, P_{1}\right)\right\} \quad$ and $F_{g}\left(I_{2}, P_{2}\right)=0$ So the government actions are decided by yield and cost. If $\left[y\left(I_{1}, P_{1}\right)-x\left(I_{1}, P_{1}\right)\right]>0$, the optimal solution of government is " $I^{*}\left(P_{1}\right)=I_{1}$ ", so government has better implement economic incentive policy. On the contrary, government had better give up the economic incentive policy.

\section{3) Results}

According to the Dynamic Game Model between government and enterprises, this paper comes up to the following conclusions.

Economic benefits are the key factor to promote enterprises investment on BIM application, when the economic benefits of BIM is better, the enterprise consciously promotes BIM applications even without the government's economic policy incentives or legal norms. The government should pay more attention to BIM technology research and the legalization of BIM standard, such as how to make the CNBIMS reasonable, how to reduce the cost of BIM applications and how to accelerate the building of the BIM platform.

When the BIM application brings more income, the Positive Externalities is a main factor that affects BIM application. One part of positive externalities yield is obtained by other enterprises; the other part is earned by the society. In the view of the former part of the external benefits (they are also the investors of application technology), they are indifferent to economic policy restrictions. However, through the formalities for examination and approval of the convenient methods, it can also promote BIM applications. According to the second part, the government can compensate to enterprises by using economic incentives so as to reach the purpose of popularizing BIM's applications.

The Economic Incentive effect is the key that affects whether the government decides to support economic incentives or not. Only when the output is greater than the incentive cost, will the government accelerate economic stimulus. On the contrary, the government will not impose economic incentive policies when the incentive cost is more than the benefit.

\section{4) The solution of government}

According to the microeconomics theory and Chinese national conditions, this paper puts forward some policy suggestions. 1) The national investment and large public utilities should adopt BIM applications and establish the access mechanism, referring to the examples of abroad and Hong Kong. 2) To the enterprises, which use BIM actively, some preferential policies are required. For example when the enterprises want to obtain the land use right more easily, government should reduce the collection of town land royalties and cultivate land usage tax. In addition, the government should speed up the examination and approve to open a green channel for these enterprises [18]. Conversely, levying taxes and extending project approval process can be enacted to those enterprises that did not use BIM. 3) Increasing the special funds to support BIM research and application. 4) Government can also encourage other enterprises to research BIM technologies. 5) Finally, government establishes an appraisal system to BIM talents and enterprises gradually.

\section{CONCLUSION}

This paper depends on economics theory, uses the method of Game theory and analyzes the economic obstacles of BIM application, and presents some solutions. Finally, it demonstrates the following:

BIM applications are hampered by positive externalities.

Participants' interests are increasing due to the Interaction Externality, but participants still do not popularize and deepen BIM applications simultaneously and consciously.

The government has the strongest power to promote BIM application and it can support some economic policy.

The economic benefit is the key factor for enterprises to invest BIM application, if the economic benefit is obvious, no matter whether the government supports economic stimulus or not, enterprises will promote BIM applications.

Only when the output is more than the incentive cost, will the government impose economic incentive policies.

\section{REFERENCE}

[1] S. Rafael, Building Information Modeling, CA, Autodesk, Inc., p. 1, 2003

[2] G.-B. Wang, Y. Zhang, Z.-J. Jiang et al., "Benefits situation to stakeholders using BIM in preconstruction stage of projects," Journal of SHANDONG JIANZHU University, pp. 438-442, 459, May 2009.

[3] C.-X. Zhang, "BIM technology application situation and development of the construction industry in our country obstacles to study," Building Economy, pp. 96-98, Sept. 2011.

[4] Y.-K. Ying, "What kind of career environment for talent plus development-The consulting team and talent plus one of BIM thinking," Journal of Information Technology in Civil Engineering and Architecture, pp. 37-39, March 2011.

[5] D.-L. Geng, "Strategy and analysis on BIM applications," Journal of Information Technology in Civil Engineering and Architecture, pp. 51-54, Feb 2011.

[6] BIM Research Group of THU, Research on Chinese Building Information Modeling Standard Framework, China Architecture \& Building Press, Beijing, China, 2011, pp. 1-4.

[7] Q.-H. He, H.-T. Pan, Y.-K. Li et al., "BIM implementation framework based on cloud computing research," Construction Economy, pp. 86-89, May 2012.

[8] J.-J. Zhu, "The research of developing actuality of BIM technology in Domestic," Electronic Test, pp. 97-99, Sept. 2013.

[9] L.-Y. Zhang, Y.-W. Li, and Y. Gao, "Barrier and countermeasures of the BIM application in China," Journal of Civil Engineering and Management, pp. 65-85, March 2013.

[10] Z.-L. Ma, "China's construction industry status, problems and countermeasures of application of BIM technology," China Survey and Design, pp. 39-42, 2013.

[11] M. Darius, P. Vladimir, J. Virgaudas et al.,"The benefits, obstacles and problems of practical bim implementation," in Proc. 11th International Conference on Modern Building Materials, Structures and Techniques ,MBMST, Procedia Engineering, 2013, pp, 767 - 774.

[12] Y.-X. Gong, "Analysed the present situation of the application of BIM in our country and the development obstacles," Electronic Commerce, pp. 104-105, Dec. 2012. 
[13] H.-Y. Gao, Microeconomic Theory: With Economic Applications and Infotrac: Basic Principles and Extensions, China Renmin University Press Co. LTD, Beijing, China, 2000, pp. 416, 422-432.

[14] M.-J. Shen and L.-Q. He, "The classification of externality and the evolvement of externality theory," Journal of Zhejiang University (Humanities and Social Sciences), pp. 152-160, 2012.

[15] K. Nassar, "Assessing building information modeling estimating techniques using data from the classroom," American Society of Civil Engineers, pp. 171-180, 2012.

[16] Smart market Report, The Business Value of BIM, McGraw-Hill Construction, Sept. 2009.

[17] $\mathrm{H}$. Li, "Research on the application architecture of BIM in building projects," Journal of Engineering Management, pp. 525-529, Oct. 2010.

[18] Z.-Y. Jin, "Economic incentive policy design for green buildings based on externality analysis," Building Sciences, pp. 57-62, June 2010.

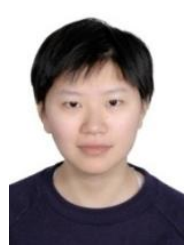

Boya Ji was born in Beijing, China in 1990. She received the B.S. degree from the Beijing University of Civil Engineering and Architecture (BUCEA) in 2012. She is currently pursuing the M.S. degree at the School of Economics and Management Engineer, BUCEA. Her research interests include BIM, engineering project management, and construction informatization.

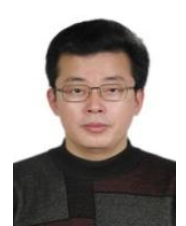

Zhenqiang Qi was born in Guangxi, China in 1973. He received the M.S. degree from Beijing Jiaotong University (BJTU). He works in BUCEA and is pursuing the Ph.D. in BJTU currently. His research interests include BIM, engineering project management, and construction informatization.

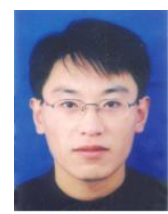

Zhanyong Jin was born in Shandong, China in 1982. He received the M.S. and Ph.D. degree from Harbin Institute of Technology (HIT). He works in BUCEA currently. His research interests include economic incentives, intellectual property rights and building energy efficiency. 